\title{
Ethylene Glycol Based Side Chain Length Engineering in Polythiophenes and its Impact on Organic Electrochemical Transistor Performance
}

Maximilian Moser, ${ }^{1 *}$ Lisa R. Savagian, ${ }^{2}$ Achilleas Savva, ${ }^{3}$ Micaela Matta, ${ }^{4}$ James F. Ponder, Jr., ${ }^{1}$ Tania Cecilia Hidalgo, ${ }^{3}$ David Ohayon, ${ }^{3}$ Rawad Hallani, ${ }^{5}$ Maryam Reisjalali, ${ }^{4}$ Alessandro Troisi, ${ }^{4}$ Andrew Wadsworth, ${ }^{1}$ John R. Reynolds, ${ }^{2}$ Sahika Inal ${ }^{3}$ and Iain McCulloch ${ }^{1,5}$

${ }^{1}$ Department of Chemistry and Centre for Plastic Electronics, Imperial College London, London, W12 0BZ, United Kingdom

${ }^{2}$ School of Materials Science \& Engineering, School of Chemistry \& Biochemistry, Center for Organic Photonics and Electronics, Georgia Tech Polymer Network, Georgia Institute of Technology, Atlanta, Georgia 30332-0100, United States

${ }^{3}$ Organic Bioelectronics Laboratory, Biological and Environmental Science and Engineering, King Abdullah University of Science and Technology (KAUST), Thuwal 23955-6900, Saudi Arabia

${ }^{4}$ Department of Chemistry, University of Liverpool, Liverpool, L69 7ZD, United Kingdom

${ }^{5}$ King Abdullah University of Science and Technology (KAUST), KAUST Solar Center, Thuwal 239556900, Saudi Arabia

E-mail: maximilian.moser13@imperial.ac.uk 


\begin{abstract}
Replacing the alkyl side chains on conventional semiconducting polymers with ethylene glycol (EG) based chains is a successful strategy in the molecular design of mixed conduction materials for bioelectronic devices, including organic electrochemical transistors (OECTs). Such polymers have demonstrated the capability to conduct both ionic and electronic charges and can offer superior performance compared to the most commonly used active material, poly $(3,4-$ ethylenedioxythiophene):poly(styrenesulfonate). While many research efforts have been dedicated to optimizing OECT performance through the engineering of the semiconducting polymers' conjugated backbones, variation of the EG chain length has been investigated considerably less. In this work, a series of glycolated polythiophenes with pendant EG chains spanning two to six EG repeat units was synthesized and the electrochemical and structural characteristics of the resulting films were characterized by experimental means and molecular dynamics simulations. OECTs were fabricated and tested, and their performance showed a strong correlation to the length of the EG side chain length, thereby elucidating important structure-property guidelines for the molecular design of future channel materials. Specifically, a careful balance in the EG length must be struck during the design of EG functionalized conjugated polymers for OECTs. While minimizing the EG side chain length appears to boost both the capacitive and charge carrier transport properties of the polymers, the chosen EG side chain length must be kept sufficiently long to induce solubility for processing, and allow for the necessary ion interactions with the conjugated polymer backbone.
\end{abstract}

\title{
1. Introduction
}

Organic electrochemical transistors (OECTs) have recently gained considerable attention due to their ability to directly transduce ionic fluxes into electronic signals. ${ }^{1-4}$ This property has enabled the development of low-voltage electronic interfaces, such as bio(chemical)-sensors and electrophysiological probes, that enable effective communication between abiotic and biotic systems. ${ }^{5-}$

${ }^{10}$ Commonly, OECTs are three-terminal electronic devices, comprising a source, drain, and gate electrode and a redox-active (voltage modulated doping state) organic semiconductor interfacing with an electrolyte solution. The working mechanism of an OECT involves bulk electrochemical doping of the polymer channel, where electrolyte fluxes occurring across the polymer-electrolyte interface are coupled to electronic charge carrier injection at the polymer-electrode interface. ${ }^{11,12}$ High-performing OECT active materials support the effective transport of mixed (i.e. electronic and ionic) charges throughout the bulk of the polymer channel. Variations in the gate potential are then responsible for varying the doping level of the channel and therefore the number of injected charge-balancing counterions in the organic semiconductor. The operation of OECTs can be described by a combination of an electronic and ionic circuit, whereby the performance of OECTs is typically evaluated in terms of their transconductance $\left(\mathrm{g}_{\mathrm{m}}\right)$, as described in Equation 1. ${ }^{11}$ 
$g_{m}=\frac{\partial I_{D}}{\partial V_{G}}=\mu C^{*} \cdot \frac{W d}{L}\left(V_{T H}-V_{G}\right)$

In this expression, $\partial I_{D}$ represents a differential source-drain current, $\partial V_{G}$ to the corresponding sourcegate voltage differential, $\mu$ is the electronic charge carrier mobility, $C^{*}$ the volumetric capacitance, $W$ the channel width, $d$ the channel depth, $L$ the channel length, $V_{G}$ the gate voltage and $V_{T H}$ the threshold voltage.

Organic semiconductors can be classified as $p$-type or $n$-type, depending on whether they transport holes or electrons, respectively. In the case of organic semiconductors used in OECTs, a further distinction is made depending on the doping level of the semiconductor under ambient conditions. In the case of a material that is not intrinsically doped, the OECT usually operates in accumulation mode, while in the case of a material that is doped under ambient conditions, the OECT typically operates in depletion mode. Although accumulation mode devices tend to be preferred, as they consume less power and require lower gate voltages for operation, ${ }^{13}$ the current workhorse OECT channel material is the polyelectrolyte dispersion poly(3,4-ethylenedioxythiophene):poly(styrenesulfonate) (PEDOT:PSS), which almost exclusively exhibits $p$-type depletion mode operation ${ }^{11}$ and frequently requires extensive pre- and post-processing to optimize polymer stability and electrochemical performance in aqueous media. ${ }^{14-16}$ Despite these drawbacks, PEDOT:PSS's commercial availability, operational stability and relatively high performance have contributed greatly to its widespread use in the bioelectronic community. ${ }^{17-19}$

Over the last few years, a new class of organic semiconductors comprising conjugated polymer backbones and solubilizing ethylene glycol (EG) derived side chains has been developed, some of which show OECT performances that rival or even exceed those of devices fabricated with PEDOT:PSS. ${ }^{19-21}$ Moreover, this class of materials offers numerous additional advantages compared to PEDOT:PSS, specifically due to: (i) the broad range of conjugated aromatic repeat units that can be employed to tune the transport properties of the organic semiconductor, ${ }^{20-24}$ (ii) the absence of any electrically insulating polyelectrolyte component, thus improving the materials' capacitance, ${ }^{19}$ (iii) the development of $n$-type organic semiconductors for OECTs, allowing for the fabrication of complementary circuits ${ }^{25,26}$ and (iv) the fabrication of electrochemical sensors integrating catalytic enzymes for the detection of biologically relevant metabolites. ${ }^{27,28}$ In EG functionalized materials, the EG side chains are not only included for the purpose of solubilizing the polymer, thus rendering it compatible with solution-based processing, but also to facilitate aqueous ion transport and stabilization during OECT operation. ${ }^{20,21}$ Given the importance of the EG side chains, it is worthwhile to note that virtually every high performing $p$-type glycolated OECT semiconductor employs the triethylene glycol motif as its side chains, with little direct comparisons against shorter or longer EG side chains made up to date. ${ }^{20-22,29}$ This is somewhat surprising, considering that modulation of the side chain length and/or branching point are common 
strategies in other areas of organic electronics, such as in organic field effect transistors and organic photovoltaics, to boost the performance of the organic semiconductor. ${ }^{30,31}$

With these considerations in mind, we developed a series of glycolated polythiophenes in which the length of the EG side chain was varied from two to six EG repeat units. This family, which was based upon the previously reported g2T-T, ${ }^{20}$ includes four materials herein referred to as (pgxT2-T) (where $x=2,3,4$ or 6). The repeat unit structures of these polymers are shown in Figure 1. We opted for an all-thiophene polymer backbone, as polymers based on this conjugated backbone have shown particularly high OECT performance. ${ }^{20}$ Moreover, we also envisaged that such a polymer backbone would provide sufficient solubility to systematically investigate the effects of both chain shortening and elongation, thus provide a more comprehensive picture of side chain length engineering. Finally, these polythiophene based structures also feature a relatively low degree of synthetic complexity, analogous to poly(3-hexylthiophene) (P3HT) - which has become a model polymer in both organic photovoltaics and organic field effect transistors - thus rendering these structures viable candidates for industrial scaleup and compete with PEDOT:PSS as model systems in organic bioelectronics. ${ }^{32-34}$

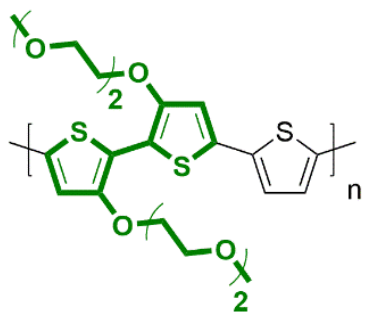

$\mathrm{p}(\mathrm{g} 2 \mathrm{~T} 2-\mathrm{T})$

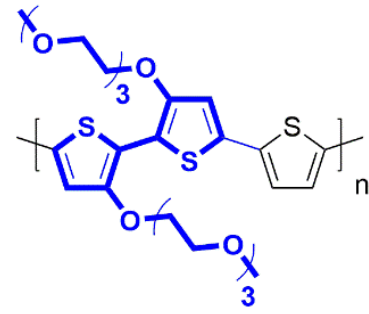

$\mathrm{p}(\mathrm{g} 3 \mathrm{~T} 2-\mathrm{T})$

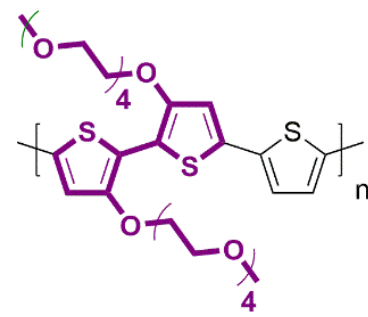

$\mathrm{p}(\mathrm{g} 4 \mathrm{~T} 2-\mathrm{T})$

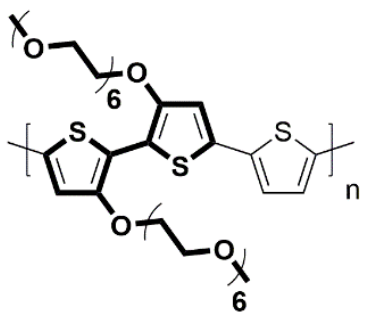

$p(g 6 T 2-T)$

Figure 1. Chemical structures of the repeat units for $\mathrm{p}(\mathrm{g} 2 \mathrm{~T} 2-\mathrm{T})$, p(g3T2-T), p(g4T2-T) and $\mathrm{p}(\mathrm{g} 6 \mathrm{~T} 2-\mathrm{T})$.

\section{Experimental Section}

Materials. The synthesis and characterization of the polymers and the various synthetic intermediates is outlined in the supporting information.

Electrochemical Analysis. Aqueous cyclic voltammetry (CV) and differential pulse voltammetry (DPV) were performed on a Reference 3000 Gamry potentiostat/galvanostat/ZRA controlled with Gamry Framework 6.5 software. For CV and DPV, samples were prepared by dissolving and drop-casting identical masses of each polymer $(16 \mu \mathrm{g})$ onto a polished glassy carbon button electrode (area $=0.07 \mathrm{~cm}^{2}$ ). All aqueous electrochemistry was performed in a $0.1 \mathrm{M}$ solution of $\mathrm{NaCl}$ (biotechnology grade, Amresco) dissolved in ultrapure water $(18.2 \mathrm{M} \Omega \cdot \mathrm{cm})$ while under an argon blanket. Prior to electrochemical studies, the electrolyte was degassed with argon for ten minutes. For $\mathrm{CV}$ and DPV, a glassy carbon rod was used as the counter electrode, and an $\mathrm{Ag} / \mathrm{AgCl}$ electrode (3 M $\mathrm{NaCl} / \mathrm{H}_{2} \mathrm{O}$ inner solution, $\mathrm{BASi}$ ) was used as the reference. For both measurements a three-electrode configuration involving a Princeton Applied Research 273A potentiostat/galvanostat was used. A 
similar set-up was employed for the electrochemical evaluation of the polymers in organic media and is described in more detail in the supporting information.

For spectroelectrochemical measurements, all polymers were cast on ITO/glass substrates ( 7 $\mathrm{mm} \times 50 \mathrm{~mm}$ x $0.7 \mathrm{~mm}$, sheet resistance $8-12 \Omega \mathrm{sq}^{-1}$, Delta Technologies Ltd). Prior to coating, the substrates were cleaned by sonicating in a solution of sodium dodecyl sulfate in DI water, followed by subsequent sonication in neat DI water, acetone, and isopropanol. Substrates were then dried under an argon stream and subsequently cleaned for 10 minutes in a $\mathrm{UV} / \mathrm{O}_{3}$ chamber. Potential-dependent UVvis-NIR absorption spectra were recorded on a Cary 5000 UV-Vis-NIR spectrophotometer in conjunction with a Princeton Applied Research 273A potentiostat/galvanostat with CorrWare software. The polymer-coated ITO electrodes were immersed in a quartz cuvette and incorporated into a 3electrode cell. The polymer-coated ITO was the working electrode, a platinum flag served as the counter electrode, and an $\mathrm{Ag} / \mathrm{AgCl}$ ( $3 \mathrm{M} \mathrm{NaCl} / \mathrm{H}_{2} \mathrm{O}$ inner solution, $\mathrm{BASi}$ ) was used as the reference. The electrolyte was a $0.1 \mathrm{M} \mathrm{NaCl}$ solution in ultrapure water $(18.2 \mathrm{M} \Omega \cdot \mathrm{cm})$. As-cast spectra were recorded at open circuit conditions immediately upon immersing the film in the electrolyte without any external bias. Prior to spectroelectrochemical measurements, the polymers were subject to 10 cyclic voltammograms $\left(-0.5\right.$ to $+0.8 \mathrm{~V}$ at $\left.50 \mathrm{mV} \mathrm{s}^{-1}\right)$ to electrochemically condition the film. Spectra were recorded under potentiostatic conditions in $100 \mathrm{mV}$ increments. Before recording the spectra, the film was held at each respective potential for 10-30 seconds, until the current transient reached a steady state.

Electrochemical impedance spectroscopy (EIS) was performed on a Reference 3000 Gamry potentiostat/galvanostat/ZRA controlled with Gamry Framework 6.5 software. Rectangular films were cast onto clean ITO/glass electrodes in the same manner described for the spectroelectrochemical studies. The polymer-coated ITO electrode was used as the working electrode, while a large stainlesssteel plate served as the counter electrode and an $\mathrm{Ag} / \mathrm{AgCl}$ electrode $\left(3 \mathrm{M} \mathrm{NaCl} / \mathrm{H}_{2} \mathrm{O}\right.$ inner solution, BASi) was employed as the reference. The cell was completed with a $0.1 \mathrm{M} \mathrm{NaCl}$ solution in ultrapure water, degassed with argon and kept under an argon blanket throughout the entirety of the EIS studies. Prior to performing EIS studies, the films were electrochemically conditioned via 10 cyclic voltammograms. A $5 \mathrm{mV}$ AC bias was superimposed on a range of DC offsets, which set a particular doping level in the polymer film. Films were held at a given potential for 60 seconds before recording the EIS spectra to ensure steady-state behavior, starting with the film in its most reduced state and increasing incrementally to its most oxidized state. EIS was performed at low frequencies $(10 \mathrm{~Hz}-0.1$ $\mathrm{Hz}$ ) to capture the capacitance associated with the faradaic doping/dedoping reaction. The lowfrequency portion of the impedance spectrum was fit with an R-CPE series circuit, where R represents the charge transfer resistance and CPE represents a constant phase element to describe the imperfect capacitive behavior of the polymer film. After EIS, the films were de-doped, rinsed with copious amounts of DI water, and dried. The film thickness was measured using a Bruker Dektak XT profilometer. The film length and width were calculated using calipers and used to calculate the overall 
volume of the dry film. The calculated capacitance, $\mathrm{C}$, was normalized to film thickness, affording the volumetric capacitance, $\mathrm{C}^{*}$.

Molecular Dynamics Simulations. Molecular dynamics (MD) simulations were performed on $\mathrm{p}(\mathrm{g} 3 \mathrm{~T} 2-\mathrm{T})$ and $\mathrm{p}(\mathrm{g} 4 \mathrm{~T} 2-\mathrm{T})$. The OPLS-AA force field was reparametrized for $\mathrm{p}(\mathrm{g} x \mathrm{~T} 2-\mathrm{T})$, with point charges, bond lengths and angles taken from DFT-optimized oligomers. Inter-ring torsions were instead taken from MP2 calculations, see the supporting information for further details. Our simulation box comprised 64 polymer chains, each made of 4 repeat units equilibrated in the NPT ensemble at $1 \mathrm{~atm}$ and $300 \mathrm{~K}$, see the supporting information for additional computational details. The oligomer length was chosen to be sufficiently long to capture orbital delocalization and polymer flexibility, without paying an excessive computational cost.

OECT Fabrication and Characterization. OECTs were fabricated following the parylene peel-off process previously described in the literature. ${ }^{20}$

All transistor properties were measured employing an aqueous $0.1 \mathrm{M} \mathrm{NaCl}$ solution as the supporting electrolyte and an $\mathrm{Ag} / \mathrm{AgCl}$ pellet electrode from Warner Instruments with a diameter of 2 $\mathrm{mm}$ and a height of $2 \mathrm{~mm}$ as the gate electrode. Output and transfer characteristics were recorded by connecting OECTs to a Keithley 2602A SourceMeter. A National Instrument NI PXIe-1062Q was used to obtain transient characteristics of the OECTs. Raw data were recorded through custom built LabVIEW software.

\section{Results and Discussion}

\subsection{Polymer Design and Synthesis}

A detailed account of the synthetic procedures can be found in the supporting information (S.I.). Briefly, the various EG-functionalized bithiophene dibromide monomers for the polymers $\mathrm{p}(\mathrm{g} 2 \mathrm{~T} 2-\mathrm{T})$, $\mathrm{p}(\mathrm{g} 3 \mathrm{~T} 2-\mathrm{T})$ and $\mathrm{p}(\mathrm{g} 4 \mathrm{~T} 2-\mathrm{T})$ were synthesized based on a previous literature procedure. ${ }^{20}$ Specifically, this involved a three-step route starting with the transetherification of 3-methoxythiophene with the corresponding EG monomethyl ether chain. Selective lithiation at the 2-position of each glycol functionalized thiophene derivative was followed by oxidative coupling employing iron(III) acetylacetonate, affording the dimerized products. ${ }^{35}$ The last step involved electrophilic bromination employing N-bromosuccinimide. For the synthesis of p(g6T2-T) the corresponding side chain was first synthesized prior to the transetherification step. Attempts to form the corresponding dimerized product by the same procedure used for the shorter EG side chain derivatives proved unsuccessful. The hexaethylene glycol functionalized bithiophene unit was instead obtained by bromination of the 2position followed by an oxidative nickel-mediated homocoupling.

The various EG functionalized bithiophene dibromide monomers were polymerized by Stille cross-coupling with 2,5-bis(trimethylstannyl)thiophene to yield the final products. As demonstrated by gel permeation chromatography (GPC), comparable molecular weights were obtained for each polymer $\left(\mathrm{M}_{\mathrm{n}}=11-28 \mathrm{kDa}\right.$ vs. polystyrene standards at $40{ }^{\circ} \mathrm{C}$ in chloroform, see S.I.). Due to the significant 
variation in the side chain length of the polymers, the polymers displayed markedly different solubilities. For instance, $\mathrm{p}(\mathrm{g} 2 \mathrm{~T} 2-\mathrm{T})$ exhibited low solubility in chloroform. Polymer $\mathrm{p}(\mathrm{g} 3 \mathrm{~T} 2-\mathrm{T})$ was readily soluble (up to $\sim 25 \mathrm{mg} / \mathrm{mL}$ ) in chloroform, while $\mathrm{p}(\mathrm{g} 4 \mathrm{~T} 2-\mathrm{T})$ dissolved in both chloroform and hot ethyl acetate. As anticipated, the polymer with the longest side chains, p(g6T2-T), was soluble in a range of organic solvents including chloroform, ethyl acetate, acetone, and methanol.

\subsection{Polymer Characterization}

The electrochemical properties of the polymers were evaluated by differential pulse voltammetry (DPV) and cyclic voltammetry (CV). Details regarding electrochemical analysis are reported in the S.I. DPV was employed to determine the onset of oxidation $\left(\mathrm{E}_{\mathrm{ox}, \mathrm{aq}}\right)$ of each material. The DPV traces recorded for each polymer can be found in Figure $\mathbf{S 5}$ in the S.I., while the $\mathrm{E}_{\mathrm{ox}, \mathrm{aq}}$ obtained for each polymer is given in Table 1. Each polymer demonstrated an $\mathrm{E}_{\text {ox,aq }}$ around $-0.2 \mathrm{~V}$ vs $\mathrm{Ag} / \mathrm{AgCl}$ with a variation of $\pm 0.1 \mathrm{~V}$ identified across the polymer series.

The cyclic voltammograms recorded for each polymer in a $0.1 \mathrm{M} \mathrm{NaCl}$ aqueous electrolyte are shown in Figure 2a. As demonstrated, each of the four derivatives can be oxidized and reduced repeatedly in water, as evidenced by the anodic and cathodic waves observed in the CV. Each of the polymers studied displayed two distinct oxidation waves within the electrochemical window of water, see Figure 2a and Figure S5 in the S.I. Typically, the first anodic wave in the CV is attributed to the oxidation of "aggregated" or "crystalline" polythiophene domains, while subsequent oxidations are thought to correspond to the oxidation of disordered or "amorphous" regions of the film. ${ }^{36,37}$

a

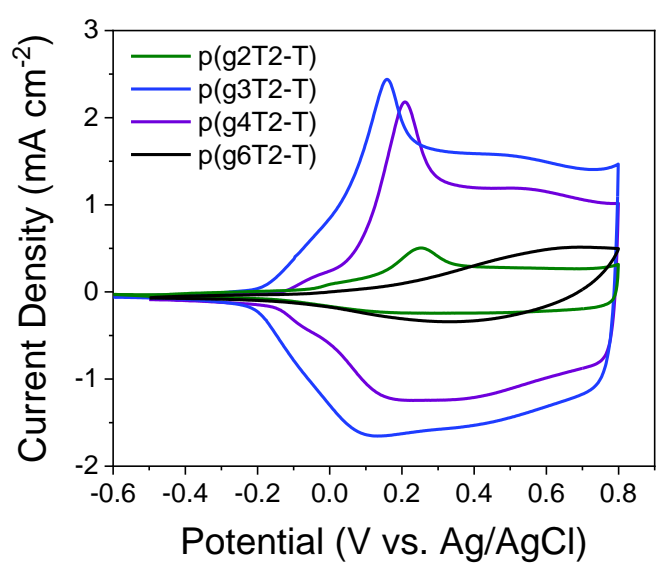

b

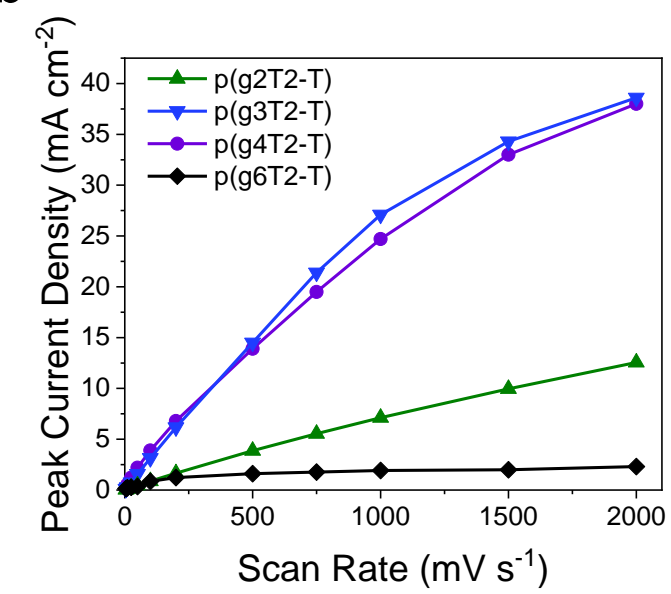

Figure 2. a) Cyclic voltammograms with a scan rate of $100 \mathrm{mV} \mathrm{s}^{-1}$ and b) peak current densities as a function of scan rate recorded for $\mathrm{p}(\mathrm{g} 2 \mathrm{~T} 2-\mathrm{T}), \mathrm{p}(\mathrm{g} 3 \mathrm{~T} 2-\mathrm{T}), \mathrm{p}(\mathrm{g} 4 \mathrm{~T} 2-\mathrm{T})$ and $\mathrm{p}(\mathrm{g} 6 \mathrm{~T} 2-\mathrm{T})$ employing a degassed aqueous $0.1 \mathrm{M} \mathrm{NaCl}$ solution as the supporting electrolyte. Current is reported normalized to the area of the electrode $\left(0.07 \mathrm{~cm}^{2}\right)$ for identical masses of polymer. 
Relative to $\mathrm{p}(\mathrm{g} 3 \mathrm{~T} 2-\mathrm{T})$, increasing or decreasing the length of the EG side chains decreased the current density upon doping. In fact, the overall current in the $\mathrm{CV}$ decreases in the following order $\mathrm{p}(\mathrm{g} 3 \mathrm{~T} 2-\mathrm{T})>\mathrm{p}(\mathrm{g} 4 \mathrm{~T} 2-\mathrm{T})>\mathrm{p}(\mathrm{g} 2 \mathrm{~T} 2-\mathrm{T}) \sim \mathrm{p}(\mathrm{g} 6 \mathrm{~T} 2-\mathrm{T})$. This finding was unexpected, considering that the electroactive masses of the polymers, i.e. the mass percentage of conjugated backbone relative to the whole polymer, were 50\%, 43\%, 37\% and 29\% for $\mathrm{p}(\mathrm{g} 2 \mathrm{~T} 2-\mathrm{T}), \mathrm{p}(\mathrm{g} 3 \mathrm{~T} 2-\mathrm{T}), \mathrm{p}(\mathrm{g} 4 \mathrm{~T} 2-\mathrm{T})$ and $\mathrm{p}(\mathrm{g} 6 \mathrm{~T} 2-\mathrm{T})$, respectively. With the greatest relative electroactive mass, polymer $\mathrm{p}(\mathrm{g} 2 \mathrm{~T} 2-\mathrm{T})$ was thus envisaged to be able to pass the highest amount of charge across one electrochemical doping-dedoping cycle. The likely reason for $\mathrm{p}(\mathrm{g} 2 \mathrm{~T} 2-\mathrm{T})$ 's reduced ability to store electronic charges is due to its short EG chains significantly increasing its aggregation, thus rendering it insoluble in the vast majority of processing solvents and potentially also less permeable to charge compensating ions. Moreover, the shorter EG chains are also likely to stabilize the charged hydrated ions to a lesser degree. The EG side chain length in $\mathrm{p}(\mathrm{g} 3 \mathrm{~T} 2-\mathrm{T})$ was sufficiently long to enable both ion penetration and storage, hence enabling it to pass the highest amount of charge in one electrochemical cycle across the polymer series. On the other hand, further increasing the side chain length led to a decrease in the electroactive fraction of the polymers, thus leading to the decrease in current density. Consequently, this means that a careful trade-off in the EG length must be achieved during the design of EG functionalized conjugated polymers for OECTs to ensure high charging capabilities. The chosen EG side chain length must be sufficiently long to allow for considerable ion interaction with the conjugated polymer backbone, yet must be kept to a minimum length to minimize the dilution of the conjugated polymer backbone to maximize the charge storage capabilities.

To evaluate the speed of these redox processes, the peak current in the CV was studied as a function of scan rate, $v$, see Figure $\mathbf{2 b}$ and Figure $\mathbf{S} 7$ in the S.I. When the charge transfer resistance between the polymer film and the electrode is assumed to be negligible, this experiment allows us to evaluate the mass transport limitations associated with the doping/dedoping process. As shown in Figure S7, p(g2T2-T), p(g3T2-T) and p(g4T2-T) all exhibited relatively linear dependencies of the peak current density on the scan rate up to $v=500 \mathrm{mV} \mathrm{s}^{-1}$, thus facilitating rapid charge and discharge kinetics, which are likely to be favorable in the context of recording short-lived biological signals with OECTs. The polymer with the shortest side chains $\mathrm{p}(\mathrm{g} 2 \mathrm{~T} 2-\mathrm{T})$ exhibits current densities that are comparable with the other materials at low scan rates $\left(v=5 \mathrm{mV} \mathrm{s}^{-1}\right)$. However, at higher scan rates, the current for this polymer is markedly lower relative to the others, despite $\mathrm{p}(\mathrm{g} 2 \mathrm{~T} 2-\mathrm{T})$ maintaining a linear scan rate dependence for high scan rates. This may suggest that polymer $\mathrm{p}(\mathrm{g} 2 \mathrm{~T} 2-\mathrm{T})$ has a lower overall concentration of accessible redox sites in the film or that the redox sites experience repulsive interactions. ${ }^{38}$ Such observation could also potentially explain the low current density and charge storage capacity for this material. Compared to the other polymers, $\mathrm{p}(\mathrm{g} 6 \mathrm{~T} 2-\mathrm{T})$ was only capable of retaining a linear dependency of the peak current density up to a scan rate around $200 \mathrm{mV} \mathrm{s}^{-1}$. Further increases in the scan rate for $\mathrm{p}(\mathrm{g} 6 \mathrm{~T} 2-\mathrm{T})$ resulted in a partial delamination and dispersion or dissolution of the polymer in the electrolyte, accounting for the low current densities at higher scan rates. 
Cyclic voltammetry was also employed as a preliminary tool to study the redox stability of the polymers. Each polymer was subjected to 100 full doping/dedoping cycles across a potential range from $-0.5 \mathrm{~V}$ to $+0.8 \mathrm{~V}$ vs $\mathrm{Ag} / \mathrm{AgCl}$ in an aqueous $0.1 \mathrm{M} \mathrm{NaCl}$ supporting electrolyte, see Figure $\mathbf{S 8}$ in the S.I., thereby simulating the conditions encountered during OECT device operation. After 100 cycles, more than $95 \%$ of the initial charge was retained for $\mathrm{p}(\mathrm{g} 2 \mathrm{~T} 2-\mathrm{T})$, $\mathrm{p}(\mathrm{g} 3 \mathrm{~T} 2-\mathrm{T})$ and $\mathrm{p}(\mathrm{g} 4 \mathrm{~T} 2-\mathrm{T})$, which suggests the suitability of these materials as mixed semiconductors for OECT applications. Similar to the data obtained from the previous electrochemical characterization experiments, $p(g 6 \mathrm{~T} 2-\mathrm{T})$ showed the lowest stability due to the partial delamination of the polymer upon repeated electrochemical cycling only retaining $80 \%$ of the initial charge. For this polymer, we hypothesize that the long side chains rendered it exceedingly polar in its doped state, causing significant swelling, delamination, and dispersion in the aqueous media upon repeated cycling. ${ }^{39}$

Table 1. Optical and electrochemical properties of the $\mathrm{p}(\mathrm{g} x \mathrm{~T} 2-\mathrm{T})$ polymer series.

$\begin{array}{lccccc}\text { Polymer } & \lambda_{\text {max,film }}(\mathrm{nm}) & \mathrm{E}_{\mathrm{g}, \text { opt }}(\mathrm{eV}) & \mathrm{E}_{\text {ox,aq }}(\mathrm{V} \mathrm{vs.} \mathrm{Ag} / \mathrm{AgCl})^{a} & \mathrm{E}_{\text {ox,org }}(\mathrm{V} \text { vs. Ag/AgCl })^{b} & \mathrm{IP}(\mathrm{eV})^{c} \\ \mathbf{p} \text { (g2T2-T) } & 602 & 1.67 & -0.10 & -0.16 & 4.50 \\ \mathbf{p} \text { (g3T2-T) } & 591 & 1.69 & -0.25 & -0.09 & 4.57 \\ \mathbf{p} \text { (g4T2-T) } & 600 & 1.69 & -0.14 & -0.02 & 4.64 \\ \mathbf{p} \text { (g6T2-T) } & 597 & 1.68 & -0.10 & 0.00 & 4.66\end{array}$

${ }^{a}$ Onset of DPV oxidation recorded in an aqueous $0.1 \mathrm{M} \mathrm{NaCl}$ electrolyte. ${ }^{b}$ Onset of $\mathrm{CV}$ oxidation recorded in a $0.1 \mathrm{M}$ TBA $\mathrm{PF}_{6} /$ acetonitrile electrolyte. ${ }^{c}$ Calculated from the equation $\operatorname{IP}(\mathrm{eV})=$ $\left(E_{\text {ox } v S F c / F c^{+}}+5.1\right) .{ }^{40}$

UV-vis absorption spectra of the dedoped form of the various polymer films were obtained while applying a $-0.8 \mathrm{~V}$ bias to ensure each polymer was in the most discharged state possible, see Figure S9. The optical properties of the fully de-doped polymers are summarized in Table 1. As indicated in Table 1, the maximum absorption wavelength ( $\left.\lambda_{\text {max,film }}\right)$ of the polymers occurred close to $600 \mathrm{~nm}$ with little variation $(\sim 10 \mathrm{~nm})$ across the polymer series. A similar trend was noted for the optical gap $\left(\mathrm{E}_{\mathrm{g}, \mathrm{opt}}\right)$ of the polymers, which was determined from the onset of absorption, giving values centered around $1.68 \pm$ $0.01 \mathrm{eV}$, thus further suggesting that EG side chain length manipulation does not strongly impact the optical properties of the polymers. The optical signatures of the various polymer films do, however, differ in their overall breadth and aggregation tendency. The polymers featuring shorter EG side chain lengths, $\mathrm{p}(\mathrm{g} 2 \mathrm{~T} 2-\mathrm{T}), \mathrm{p}(\mathrm{g} 3 \mathrm{~T} 2-\mathrm{T})$ and $\mathrm{p}(\mathrm{g} 4 \mathrm{~T} 2-\mathrm{T})$, all feature a structured $\pi-\pi^{*}$ absorption band with a lowenergy shoulder that we ascribed to the $0-0$ transition. The optical trace of the polymer with the longer EG chains, $\mathrm{p}(\mathrm{g} 6 \mathrm{~T} 2-\mathrm{T})$, did not show such a structure. The lack of vibrational fine structure in $\mathrm{p}(\mathrm{g} 6 \mathrm{~T} 2-$ T) was ascribed to a reduced molecular aggregation of the polymer in the solid state, which reduces the extent of coupling between and across chromophore segments, giving rise to an unstructured absorption spectrum. 
The electrochromic characteristics and doping mechanism of the polymer series were studied by spectroelectrochemical measurements. Polymer films were cast from solution on an ITO/glass electrode and configured into a 3-electrode cell with a $0.1 \mathrm{M}$ aqueous $\mathrm{NaCl}$ electrolyte. All as-cast spectra (i.e. no biasing) show some degree of polaronic absorbance in the NIR ( 800-1200 nm), which indicates that the film is partially doped under ambient conditions, see Figure S10. Each of the as-cast films required the application of a negative potential to completely de-dope the film as noted above. Overall, the electrochromic response of each polymer was very similar. Application of an increasingly positive potential up to $+0.5 \mathrm{~V}$ led to a reduction of the $\pi-\pi^{*}$ absorption centered around $600 \mathrm{~nm}$, with the concomitant appearance of an absorption feature at longer wavelengths peaking around $900 \mathrm{~nm}$, which was attributed to charged species of the polymers, including their polaronic and bipolaronic forms. ${ }^{41,42}$ Upon further increasing the potential to $+0.8 \mathrm{~V}$, all polymers exhibited minimal absorption in the visible range. This indicates that all materials, regardless of the length of the EG side chain, can all be fully doped within the electrochemical window of water.

A more complete picture of the interrelated factors governing the properties of these materials were obtained by $\mathrm{x}$-ray scattering techniques to probe the intermolecular ordering of the polymers in the solid state. Grazing-incidence wide angle x-ray scattering (GIWAXS) was performed to study the microstructure of the films, revealing noticeable differences in the scattering intensity and pattern depending on the length of the EG side chain. Sample preparation and data analysis are outlined in the S.I. Due to the reduced solubility of $\mathrm{p}(\mathrm{g} 2 \mathrm{~T} 2-\mathrm{T})$, homogenous films for GIWAXS analysis could not be prepared, thus excluding this polymer from any additional analysis. The scattering patterns recorded for the various polymers can be found in Figure S11. Since the most significant scattering intensities were observed in the out-of-plane scattering direction, a $\mathrm{q}_{\mathrm{z}}$ cake-slice was integrated and corrected with a sine modification to yield out-of-plane line-cuts, see Figure S11 in the S.I. These line-cuts were used to calculate the corresponding lattice spacings tabulated in Table 2.

As indicated in Figure S11, p(g3T2-T) and p(g4T2-T) were the only two polymers to display a (010) scattering peak in the out-of-plane direction, arising from the $\pi$ - $\pi$ stacking within the crystallites, with a d spacing around $3.55 \AA$. p (g6T2-T) on the other hand did not show any (010) peak in its scattering pattern, thus suggesting that $\mathrm{p}(\mathrm{g} 3 \mathrm{~T} 2-\mathrm{T})$ and $\mathrm{p}(\mathrm{g} 4 \mathrm{~T} 2-\mathrm{T})$ had a more ordered microstructure, which was consistent with the data obtained from thin-film UV-vis analysis. Polymer p(g3T2-T) also displayed an in-plane (010) scattering peak, therefore indicating that $\mathrm{p}(\mathrm{g} 3 \mathrm{~T} 2 \mathrm{~T}-\mathrm{T})$ assumes a mixed face on/edge on orientation, while $\mathrm{p}(\mathrm{g} 4 \mathrm{~T} 2-\mathrm{T})$ solely adopts a face on-orientation. These findings are in accord with literature, which has demonstrated that polymers with higher solubilities in the processing solvent prefer to orient in a face-on rather than edge-on orientation. ${ }^{43,44}$

In addition to the (010) scattering peaks, $\mathrm{p}(\mathrm{g} 3 \mathrm{~T} 2-\mathrm{T})$ and $\mathrm{p}(\mathrm{g} 4 \mathrm{~T} 2-\mathrm{T})$ also showed two orders of lamellar scattering peaks in the out-of-plane direction, which was indicative of regular ordering of side chains within the lamellae. Similarly, polymer p(g6T2-T) also displayed two orders of lamellar scattering peaks, (100) and (200). Interestingly, the lamellar spacing calculated for p(g6T2-T) was 
similar to that of $\mathrm{p}(4 \mathrm{~T} 2-\mathrm{T})$, even though the side chains are significantly longer. This suggests possible interdigitation or increased coiling of the glycol-based side chains in $\mathrm{p}(\mathrm{g} 6 \mathrm{~T} 2-\mathrm{T})$.

Table 2. Estimated lattice spacing and texture for the glycolated polythiophenes extracted from out-of-plane GIWAXS line-cuts. Values reported are the average of two films, cast and measured separately. Spacing was calculated using the equation $d=2 \pi / q_{z}$, where $q_{z}$ corresponds to the scattering vector of maximum scattering intensity. The standard error corresponds to the standard deviation of two measurements divided by two.

\begin{tabular}{llcccc} 
& & \multicolumn{2}{c}{ Lamellar stacking } & \multicolumn{2}{c}{$\pi-\pi$ stacking } \\
\cline { 3 - 6 } Polymer & Texture & $\mathrm{d}_{(100)}$ & Std. Error & $\mathrm{d}_{(010)}$ & Std. Error \\
& & $(\AA)$ & $(\AA)$ & $(\AA)$ & $(\AA)$ \\
$\mathbf{p}($ g3T2-T) & Mixed edge- and face-on & 16.3 & 0.04 & 3.56 & 0.02 \\
$\mathbf{p}($ g4T2-T) & Face-on & 24.4 & 0.20 & 3.54 & 0.01 \\
$\mathbf{p}($ g6T2-T) & n/a & 23.8 & 0.25 & n/a & n/a
\end{tabular}

\subsection{Molecular Dynamics Simulations}

Molecular dynamics (MD) simulations were employed to elucidate the effect of the EG side chain length on the short-range intermolecular interactions and aggregation behavior of the $\mathrm{p}(\mathrm{g} x \mathrm{~T} 2-\mathrm{T})$ series. We chose to focus on $\mathrm{p}(\mathrm{g} 3 \mathrm{~T} 2-\mathrm{T})$ and $\mathrm{p}(\mathrm{g} 4 \mathrm{~T} 2-\mathrm{T})$ since these appeared to be the most promising for use as OECT channel materials given their ability to pass the highest amount of charge across one electrochemical doping-dedoping cycle. Moreover, these polymers also displayed the most similar $\mathrm{M}_{\mathrm{n}}$ $\left(\mathrm{M}_{\mathrm{n}}\right.$ for $\mathrm{p}(\mathrm{g} 3 \mathrm{~T} 2-\mathrm{T})=22.6 \mathrm{kDa}, \mathrm{M}_{\mathrm{n}}$ for $\left.\mathrm{p}(\mathrm{g} 4 \mathrm{~T} 2-\mathrm{T})=28.0 \mathrm{kDa}\right)$, as determined by $\mathrm{GPC}$, and morphological properties, as indicated by GIWAXS analysis, thus enabling for the most fair comparison. The OPLS-AA force field was reparametrized for $\mathrm{p}(\mathrm{g} x \mathrm{~T} 2-\mathrm{T})$, with point charges, bond lengths and angles taken from DFT-optimized oligomers. Inter-ring torsions were instead taken from MP2 calculations, see S.I. and Figure S12. Our simulation box comprised 64 polymer chains, each made of 4 repeat units equilibrated in the NPT ensemble at $1 \mathrm{~atm}$ and $300 \mathrm{~K}$, see Figure 3a and the S.I. for computational details. The oligomer length was chosen to be sufficiently long to capture orbital delocalization and polymer flexibility, without paying an excessive computational cost.

It has been previously reported that increases in side chain lengths can lead to an increase in the conjugated backbone flexibility, resulting in more coiled conformations. ${ }^{45,46}$ This observation can be explained considering that an increase in the side chain fraction results in a corresponding increase in their self-interaction tendency, tilting the balance away from polymer chain $\pi$-stacking, which in turn also allows the polymers to overcome some of the energetic torsional penalties arising from a non-planar conjugated polymer backbone. Similarly, when comparing the backbone end-to-end distances of $\mathrm{p}(\mathrm{g} 3 \mathrm{~T} 2-\mathrm{T})$ and $\mathrm{p}(\mathrm{g} 4 \mathrm{~T} 2-\mathrm{T})$ oligomers, we observe a shift towards lower end-to-end distances as the side chain length increases, see Figure 3b, and a decrease in the persistence length from $61 \AA$ to $39 \AA$, see 
Figure S13. It is to be expected that an increase in the side chain length would hinder inter-chain backbone interactions. This effect can be visualized in the radial distribution function of thiophene rings, see Figure 3c, where the short distance peak of p(g4T2-T) is lower in intensity than for p(g3T2-T). We then took a closer look at intermolecular thiophene interactions by calculating the average fraction of rings engaged in $\pi$-stacking, $\left\langle\mathrm{f}_{\pi}>\right.$, normalized against the total number of thiophenes in the simulation box, see S.I. for details. The histograms in Figure 3d show that on average roughly 1/3 of p(g4T2-T) thiophenes are $\pi$-stacking against $2 / 3$ of $\mathrm{p}(\mathrm{g} 3 \mathrm{~T} 2-\mathrm{T})$ 's thiophene rings. This observation is consistent with the differences in chain flexibility and conformational disorder between $\mathrm{p}(\mathrm{g} 3 \mathrm{~T} 2-\mathrm{T})$ and $\mathrm{p}(\mathrm{g} 4 \mathrm{~T} 2-\mathrm{T})$, which cannot only be explained by the increase in the volume fraction of the side chains. To summarize, our MD simulation results seem to point towards a lower degree of short-range order in $\mathrm{p}(\mathrm{g} 4 \mathrm{~T} 2-\mathrm{T})$, which would agree with previous observations for side chain length trends in conjugated polymers. ${ }^{31,45}$

a

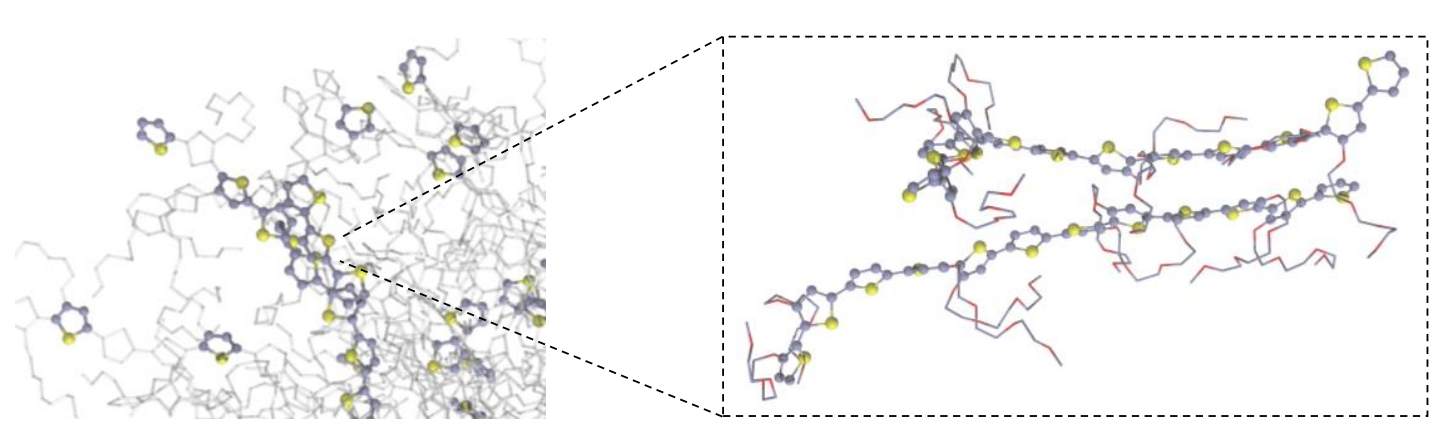

b

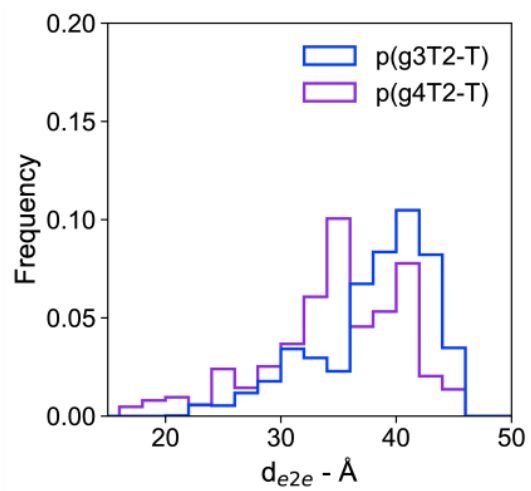

C

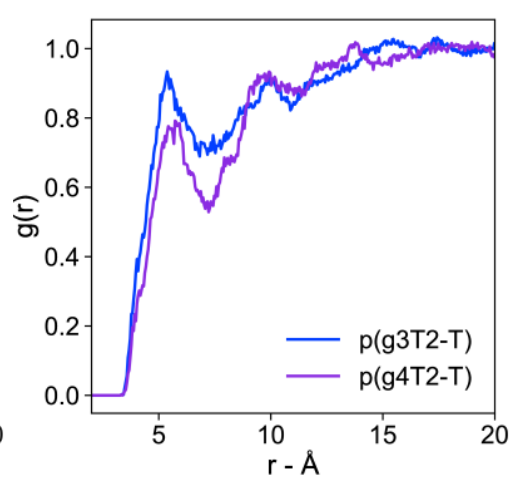

d

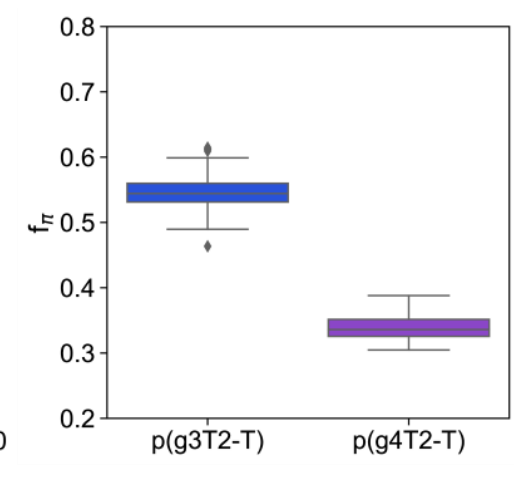

Figure 3. a) MD snapshots for $\mathrm{p}(\mathrm{g} 3 \mathrm{~T} 2-\mathrm{T})$ highlighting a section of the simulation box and the interaction between two oligomers. b) Histogram of end-to-end distances $d_{\text {E2E }}$ of p(g3T2-T) (blue) and p(g4T2-T) (purple). c) Radial distribution function between thiophenes calculated using the center of geometry of thiophene rings as reference. d) Box plot showing the average fraction of $\pi$-stacking thiophenes, $f_{\pi}$.

After having characterized the structural disorder of amorphous aggregates, we turned our attention toward the electronic states and energetic disorder of $\mathrm{p}(\mathrm{g} 3 \mathrm{~T} 2-\mathrm{T})$ and $\mathrm{p}(\mathrm{g} 4 \mathrm{~T} 2-\mathrm{T})$. Figure S16 shows the DOS of $\mathrm{p}(\mathrm{g} 3 \mathrm{~T} 2-\mathrm{T})$ and $\mathrm{p}(\mathrm{g} 4 \mathrm{~T} 2-\mathrm{T})$ calculated using a collection of 26 snapshots from each MD simulation and a gaussian smearing of $2 \mathrm{meV}$. A comparison of the two DOS plots shows a shift 
towards higher energies for $\mathrm{p}(\mathrm{g} 3 \mathrm{~T} 2-\mathrm{T})$, which would indicate that this system is easier to dope and is thus in agreement with the $\mathrm{CV}$ results discussed earlier. We also quantified the spatial extent of orbital delocalization using the inverse participation ratio per monomer IPR $\mathrm{R}_{M}$ and the localization length LL. The distribution of $\mathrm{IPR}_{\mathrm{M}}$ and LL as a function of the energy of the corresponding state are shown in Figure S16; the two polymers do not show significant differences in orbital localization within the conduction band, indicating that the higher conformational disorder seen in $\mathrm{p}(\mathrm{g} 4 \mathrm{~T} 2-\mathrm{T})$ mainly affects the band edge states without disrupting the orbital delocalization in deeper energy levels.

In summary, we have characterized the energetic and conformational landscape of $p(g 3 T 2-T)$ and $\mathrm{p}(\mathrm{g} 4 \mathrm{~T} 2-\mathrm{T})$ and our results support experimental findings showing that even a small difference in the EG side chain length could result in a different microstructure and aggregation behavior for these two systems. These subtle trends are already visible for the oligomers simulated here, so we can expect longer polymers to exhibit even larger differences. Regarding the electronic charge transport trends of $\mathrm{p}(\mathrm{g} 3 \mathrm{~T} 2-\mathrm{T})$ and $\mathrm{p}(\mathrm{g} 4 \mathrm{~T} 2-\mathrm{T})$, it has been previously shown that more rigid polymers have improved mobilities both because bends in the polymer backbone acting as traps ${ }^{47}$ and the intrinsic nature of diffusion along worm-like polymer chains. ${ }^{48} \mathrm{We}$ would also expect dynamic disorder to negatively affect the mobility of more disordered oligomer chains, thus further depressing the charge transport rate of $\mathrm{p}(\mathrm{g} 4 \mathrm{~T} 2-\mathrm{T})$ with respect to $\mathrm{p}(\mathrm{g} 3 \mathrm{~T} 2-\mathrm{T})$. Finally, our computational study does not consider the effect of water and electrolyte swelling, which are expected to mainly affect the microstructure of amorphous domains. It has been shown that swelling results in an overall decrease in the electronic charge carrier mobility of conjugated polymers, due to a decrease in the interconnectivity of polymer chains. ${ }^{29,49}$ The degree to which amorphous domains of $\mathrm{p}(\mathrm{g} 4 \mathrm{~T} 2-\mathrm{T})$ and $\mathrm{p}(\mathrm{g} 3 \mathrm{~T} 2-\mathrm{T})$ would be affected by swelling will be the subject of further studies.

\subsection{OECT Fabrication and Evaluation}

OECT channels (100 $\mu \mathrm{m}$ width $\times 10 \mu \mathrm{m}$ length) employing each polymer in the series were fabricated according to literature procedures. ${ }^{20}$ In each case, the organic semiconductor was deposited by spin-coating from $4 \mathrm{mg} / \mathrm{mL}$ polymer solutions without any annealing treatments. The increased solubility of $\mathrm{p}(\mathrm{g} 6 \mathrm{~T} 2-\mathrm{T})$ compared to the other polymers, resulted in significant delamination issues, thus preventing the fabrication of OECTs stable for operation in aqueous electrolytes. Devices were operated using an aqueous $0.1 \mathrm{M} \mathrm{NaCl}$ solution as the supporting electrolyte and an $\mathrm{Ag} / \mathrm{AgCl}$ pellet couple as the gate electrode. Full details of the OECT fabrication and operating process can be found in the S.I.

The steady-state characteristics of the OECTs comprising these polymers in the channel are summarized in Table 3, while the recorded output, transfer and transconductance curves can be found in Figure S17 in the S.I. and Figure 4, respectively. As previously highlighted in Equation 1, the transconductance is given by the product of a device geometry term $\left(\frac{W d}{L}\right)$ and a material dependent term $\left(\left[\mu \mathrm{C}^{*}\right]\right)$ that is also a function of the oxidation state of the polymer. ${ }^{19}$ To exclude any geometry related 
effects on device performance, thus allowing for a fairer and more appropriate performance comparison between the different polymers, we have reported device performance in terms of the product $\left[\mu \mathrm{C}^{*}\right] .{ }^{19}$

a

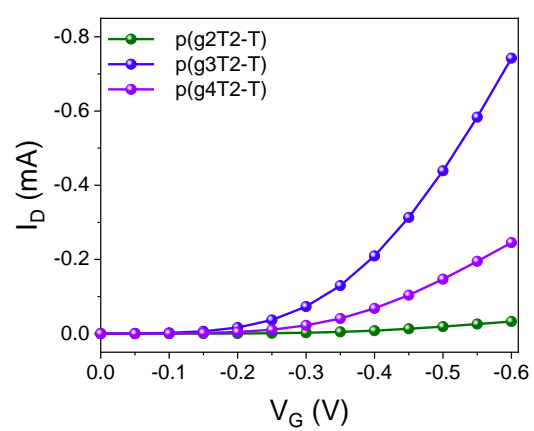

b

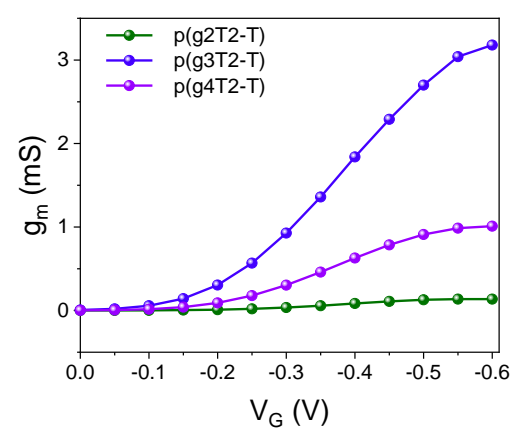

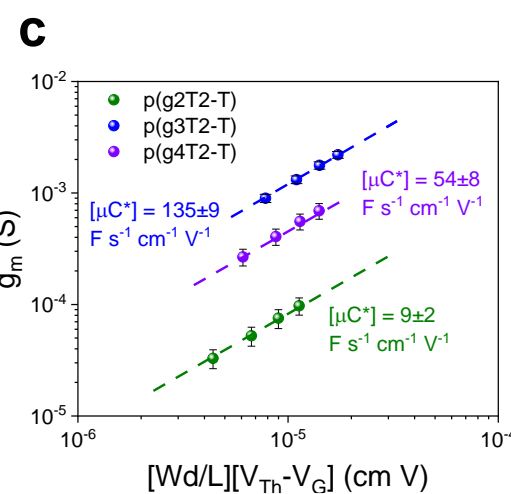

Figure 4. Representative a) transfer and b) transconductance curves recorded for a single channel of $\mathrm{p}(\mathrm{g} 2 \mathrm{~T} 2-\mathrm{T}), \mathrm{p}(\mathrm{g} 3 \mathrm{~T} 2-\mathrm{T})$ and $\mathrm{p}(\mathrm{g} 4 \mathrm{~T} 2-\mathrm{T})$. For both plots and for all polymers a $\mathrm{V}_{\mathrm{D}}$ of $-0.6 \mathrm{~V}$ and a $\mathrm{V}_{\mathrm{G}}$ step of $-0.05 \mathrm{~V}$ with a sweep rate of $-0.1 \mathrm{~V} \mathrm{~s}^{-1}$ were employed. The reported data corresponds to the data recorded during the third $I-V$ scan of each channel. c) Transconductance versus channel geometry and operating parameters plot of $\mathrm{p}(\mathrm{g} 2 \mathrm{~T} 2-\mathrm{T}), \mathrm{p}(\mathrm{g} 3 \mathrm{~T} 2-\mathrm{T})$ and $\mathrm{p}(\mathrm{g} 4 \mathrm{~T} 2-\mathrm{T})$ from which their corresponding $\left[\mu \mathrm{C}^{*}\right]$ were extracted.

Table 3. Steady-state and transient characteristics of OECTs fabricated with $\mathrm{p}(\mathrm{g} 2 \mathrm{~T} 2-\mathrm{T}), \mathrm{p}(\mathrm{g} 3 \mathrm{~T} 2-\mathrm{T})$ and $\mathrm{p}(\mathrm{g} 4 \mathrm{~T} 2-\mathrm{T})$.

$\begin{array}{lcccccccc}\text { Polymer } & \begin{array}{c}\mathrm{d} \\ (\mathrm{nm})\end{array} & \begin{array}{c}\mathrm{gm}_{\mathrm{m}}^{\dagger} \\ (\mathrm{mS})\end{array} & \begin{array}{c}{\left[\mu \mathrm{C}^{*}\right]^{\dagger, *}} \\ \left(\mathrm{~F} \mathrm{~cm}^{-1} \mathrm{~V}^{-1} \mathrm{~s}^{-1}\right)\end{array} & \begin{array}{c}\mu^{\dagger, \uparrow} \\ \left(\mathrm{cm}^{2} \mathrm{~V}^{-1} \mathrm{~s}^{-1}\right)\end{array} & \begin{array}{c}\mathrm{C}^{*, \S} \\ \left(\mathrm{F} \mathrm{cm}^{-3}\right)\end{array} & \begin{array}{c}\mathrm{On} / \\ \text { off }\end{array} & \begin{array}{c}\mathrm{V}_{\mathrm{Th}^{\dagger}}^{\dagger, *} \\ (\mathrm{~V})\end{array} & \begin{array}{c}\tau_{\mathrm{ON}} \\ (\mathrm{ms})\end{array} \\ \text { p(g2T2-T) } & 46 & 0.12 \pm 0.01 & 9 \pm 2 & \sim 10^{-4} & 8 \pm 2 & 10^{4} & -0.20 \pm 0.01 & - \\ \text { p(g3T2-T) } & 63 & 3.03 \pm 0.21 & 135 \pm 9 & 0.16 \pm 0.01 & 211 \pm 18 & 10^{5} & -0.18 \pm 0.01 & 0.91 \\ \text { p(g4T2-T) } & 53 & 0.88 \pm 0.14 & 54 \pm 8 & 0.06 \pm 0.01 & 192 \pm 10 & 10^{5} & -0.19 \pm 0.01 & 0.59\end{array}$

${ }^{\dagger}$ Average values calculated across four channels. ${ }^{\star}$ Calculated from the slope of the transconductance as a function of $\left[\left(\frac{W d}{L}\right)\left(V_{T h}-V_{G}\right)\right]$. "Mobility values were calculated by an impedance matching method, as detailed in previous literature. ${ }^{50}{ }^{\S}$ Reported volumetric capacitance values are the peak values recorded from electrochemical impedance spectroscopy. ${ }^{p}$ The mobility of $\mathrm{p}(\mathrm{g} 2 \mathrm{~T} 2-\mathrm{T})$ was too low to be determined accurately. ${ }^{*}$ Determined from the extrapolation of the linear regime of the $\mathrm{I}_{\mathrm{D}}{ }^{0.5} \mathrm{vs} \mathrm{V}_{\mathrm{G}}$ plot.

Devices with similar thicknesses of around $50 \mathrm{~nm}$ were fabricated for $\mathrm{p}(\mathrm{g} 2 \mathrm{~T} 2-\mathrm{T}), \mathrm{p}(\mathrm{g} 3 \mathrm{~T} 2-\mathrm{T})$ and $\mathrm{p}(\mathrm{g} 4 \mathrm{~T} 2-\mathrm{T})$. As demonstrated in Figure 4, each of the evaluated polymers operates in accumulation mode with the devices being off at a $\mathrm{V}_{\mathrm{G}}$ of $0 \mathrm{~V}$ and turning on upon the application of a gate potential around $-0.2 \mathrm{~V}$. No significant fluctuation in the threshold voltage was noted upon variation of the EG side chain length, thus supporting the results obtained from cyclic and differential pulse voltammetry. 
The average $\left[\mu \mathrm{C}^{*}\right]$ recorded for $\mathrm{p}(\mathrm{g} 2 \mathrm{~T} 2-\mathrm{T}), \mathrm{p}(\mathrm{g} 3 \mathrm{~T} 2-\mathrm{T})$ and $\mathrm{p}(\mathrm{g} 4 \mathrm{~T} 2-\mathrm{T})$ were $9 \pm 2,135 \pm 9$ and $54 \pm 8 \mathrm{~F} \mathrm{~cm}^{-1} \mathrm{~V}^{-1} \mathrm{~s}^{-1}$, respectively, thus demonstrating that the polymer featuring the widely employed triethylene glycol side chains showed the best performance. Note that the value recorded for p(g3T2-T) was in line with previously reported data and compares well with other high-performance p-type glycolated semiconductors for OECT applications, e.g. p(g2T-TT) and P3MEEMT, which have been reported to have a $\left[\mu \mathrm{C}^{*}\right]$ of 261 and $49 \mathrm{~F} \mathrm{~cm}^{-1} \mathrm{~V}^{-1} \mathrm{~s}^{-1}$ respectively. ${ }^{19,21,49}$ Similar trends in the performance of the materials were obtained when multiplying the product of the electronic mobility, $\mu$, and the independently-measured volumetric capacitance $\left(\mathrm{C}^{*}\right)$ as performance metric, with $\mathrm{p}(\mathrm{g} 3 \mathrm{~T} 2-\mathrm{T})$ again affording the highest value.

To gain further insights into the origin of the performance difference across the polymer series, we individually compared the results obtained for $\mathrm{C}^{*}$ and $\mu$ across the polymers. $\mathrm{C}^{*}$ values were determined by electrochemical impedance spectroscopy (EIS) on polymer films, see Figure S19. The peak $C^{*}$ values measured for each polymer are reported in Table 3. In full agreement with the results obtained from $\mathrm{CV}$, in which the current across each doping/dedoping cycle was monitored, p(g3T2-T) gave the highest $\mathrm{C}^{*}$ of $211 \pm 18 \mathrm{~F} \mathrm{~cm}^{-3}$, while $\mathrm{p}(\mathrm{g} 2 \mathrm{~T} 2-\mathrm{T})$ and $\mathrm{p}(\mathrm{g} 4 \mathrm{~T} 2-\mathrm{T})$ yielded lower values of $8 \pm 2$ and $192 \pm 10 \mathrm{~F} \mathrm{~cm}^{-3}$, respectively. In the case of $\mathrm{p}(\mathrm{g} 2 \mathrm{~T} 2-\mathrm{T})$, the low $\mathrm{C}^{*}$ was attributed to the reduced side chain length being insufficient to enable efficient ion transport and stabilization into the polymer film. On the other hand, the longer side chain length of $\mathrm{p}(\mathrm{g} 4 \mathrm{~T} 2-\mathrm{T})$, did not contribute to additional ion stabilization, thus only leading to a decrease in the proportion of electroactive mass of the polymer, consequently leading to a reduced $\mathrm{C}^{*}$. It is worthwhile to note that normalizing the $\mathrm{C}^{*}$ values obtained for $\mathrm{p}(\mathrm{g} 3 \mathrm{~T} 2-\mathrm{T})$ and $\mathrm{p}(\mathrm{g} 4 \mathrm{~T} 2-\mathrm{T})$ by the relative percentages of electroactive mass present in each polymer, i.e. $43 \%$ and $37 \%$ respectively, afforded similar electroactive mass normalized volumetric capacitances around $490 \mathrm{~F} \mathrm{~cm}^{-3}$, thus supporting the aforementioned hypothesis.

The mobility $(\mu)$ of each polymer in its doped state affording the highest transconductance in the OECT channel was determined by the impedance matching method, as detailed in previous literature. $^{51,52}$ As illustrated in Table 3, p(g3T2-T) had an almost three-fold higher $\mu$ compared to $\mathrm{p}(\mathrm{g} 4 \mathrm{~T} 2-\mathrm{T})$. Given the virtually identical $\pi-\pi$ stacking distances recorded for $\mathrm{p}(\mathrm{g} 3 \mathrm{~T} 2-\mathrm{T})$ and $\mathrm{p}(\mathrm{g} 4 \mathrm{~T} 2-\mathrm{T})$ by GIWAXS, we excluded any differences in the $\pi-\pi$ stacking distances as a reason for the improved mobilities. Instead, we speculate that as for other polythiophene based materials, p(g3T2-T)'s higher $\mu$ is a result of its preferential edge-on rather than face-on orientation on the substrates, in which the lamellae pack along the substrate, thus leading to improved charge carrier transport between the source and drain electrodes..$^{53}$ Moreover, as suggested by our computational simulations, p(g3T2-T)'s longer end-to-end conjugated backbone distances, hence more rigid polymer backbone, and its higher propensity to form $\pi$-stacked aggregates may also contribute to its improved charge carrier mobility.

The steady-state OECT characteristics were also complemented with the transient characteristics. Specifically, this involved recording the switching times $\left(\tau_{\mathrm{ON}}\right)$ for the devices. As switching times are dependent on the thickness of the active layer, devices with similar active layer 
thickness were compared for this study. ${ }^{2}$ Due to the low OECT performance of $\mathrm{p}(\mathrm{g} 2 \mathrm{~T} 2 \mathrm{~T}-\mathrm{T})$ as OECT channel material, it was not possible to reproducibly measure the switching time and cut-off frequency. As follows from Table 3, increasing the side chain length from three to four EG units led to devices that exhibited faster switching times.

\section{Conclusions}

In conclusion, four glycolated polythiophenes functionalized with EG chains ranging between two to six EG repeat units were developed to investigate how OECT performance is affected by altering the length of the pendant EG side chains. As determined by cyclic voltammetry and further confirmed by spectroelectrochemistry, each of the derivatives can be oxidized and reduced repeatedly in water, thus indicating the suitability of each polymer as OECT channel material. Nonetheless, significant variations in the amount of charge passed across one electrochemical doping-dedoping cycle were noted across the polymer series, with the triethylene glycol functionalized polymer, $\mathrm{p}(\mathrm{g} 3 \mathrm{~T} 2-\mathrm{T})$, passing the highest amount of charge. Both decreasing and increasing the EG side chain length from this optimum length, proved detrimental, suggesting that a careful balance in the EG length must be attained during the design of EG functionalized conjugated polymers for OECTs to maximize their charging capabilities.

In addition to having more promising electrochemical properties, GIWAXS analysis of the polymers also suggested $\mathrm{p}(\mathrm{g} 3 \mathrm{~T} 2-\mathrm{T})$ to have a more favorable microstructure compared to the other members of the series, with $\mathrm{p}(\mathrm{g} 3 \mathrm{~T} 2-\mathrm{T})$ showing both a high degree of lamellar ordering and a relatively high contribution of edge-on oriented crystallites, which should benefit its charge transport properties. These morphological findings were supported by MD simulations on oligomers of the polymers, which indicated that the conjugated polymer backbones of $\mathrm{p}(\mathrm{g} 3 \mathrm{~T} 2-\mathrm{T})$ oligomers assume more rigid conformations, resulting in longer backbone end-to-end distances and decreased persistence lengths, ultimately leading to a higher fraction of oligomers that can $\pi-\pi$ stack.

Finally, OECTs were fabricated and evaluated, and demonstrated that modulation of the pendant EG chains had effects on both the polymers' $C^{*}$ and $\mu$ values. For both metrics, reducing the EG side chain length to the shortest possible length that still enabled efficient OECT operation was beneficial, as this maximized both $\mathrm{C}^{*}$ and $\mu$. Nonetheless, the EG chains had to be kept sufficiently long to enable for favorable ion-polymer interactions, thus implying that these factors must be carefully balanced to find an optimum EG side chain length. Ultimately, this resulted in $\mathrm{p}(\mathrm{g} 3 \mathrm{~T} 2-\mathrm{T})$ to incur the highest OECT performance, affording a $\left[\mu \mathrm{C}^{*}\right]$ of $135 \pm 9 \mathrm{~F} \mathrm{~cm}^{-1} \mathrm{~V}^{-1} \mathrm{~s}^{-1}$.

\section{Supporting Information}

The Supporting Information is available free of charge. 
${ }^{1} \mathrm{H}$ and ${ }^{13} \mathrm{C}\left\{{ }^{1} \mathrm{H}\right\}$ NMR spectra, MALDI measurements, GPC traces, DPV traces, CV traces, GIWAXS patterns, MD simulations and OECT characterization plots can be found in the supporting information.

\section{Acknowledgements}

We acknowledge generous funding from KAUST for financial support. The research reported in this publication was supported by funding from King Abdullah University of Science and Technology Office of Sponsored Research (OSR) under awards no. OSR-2018-CARF/CCF-3079, no. OSR-2015-CRG4-2572 and OSR-4106 CPF2019. We acknowledge EC FP7 Project SC2 (610115), EC H2020 (643791), and EPSRC Projects EP/G037515/1, EP/M005143/1, and EP/L016702/1. J.R.R. acknowledges funding of this work from the Office of Naval Research (N00014-18-1-2222) and the Air Force Office of Scientific Research (FA9550-18-1-0184). L.R.S. was supported by the National Science Foundation Graduate Research Fellowship under Grant No. DGE-1650044. M. M. acknowledges the financial support of the Royal Society in the form of a Newton International Fellowship (NIF\R1\181379). Use of the Stanford Synchrotron Radiation Lightsource, SLAC National Accelerator Laboratory, is supported by the U.S. Department of Energy, Office of Science, Office of Basic Energy Sciences under Contract No. DEAC02-76SF00515. S.I. acknowledges funding from KAUST Office of Sponsored Research (OSR) under Award No. OSR-2018-CRG7-3709. We gratefully thank Dr. Sandra Pittelli for assistance with GIWAXS collection. 


\section{References}

1 Rivnay, J.; Inal, S.; Salleo, A.; Owens, R. M.; Berggren, M.; Malliaras, G. G. Organic Electrochemical Transistors. Nat. Rev. Mater. 2018, 3, 17086.

2 Moser, M.; Ponder, J. F.; Wadsworth, A.; Giovannitti, A.; McCulloch, I. Materials in Organic Electrochemical Transistors for Bioelectronic Applications: Past, Present, and Future. $A d v$. Funct. Mater. 2019, 29, 1807033.

3 Zeglio, E.; Inganäs, O. Active Materials for Organic Electrochemical Transistors. Adv. Mater. 2018, 30, 1800941.

4 Sun, H.; Gerasimov, J.; Berggren, M.; Fabiano, S. N-Type Organic Electrochemical Transistors: Materials and Challenges. J. Mater. Chem. C 2018, 6, 11778-11784.

5 Strakosas, X.; Bongo, M.; Owens, R. M. The Organic Electrochemical Transistor for Biological Applications. J. Appl. Polym. Sci. 2015, 132, 41735.

6 Martin, D. C.; Malliaras, G. G. Interfacing Electronic and Ionic Charge Transport in Bioelectronics. ChemElectroChem 2016, 3, 686-688.

7 Khodagholy, D.; Doublet, T.; Quilichini, P.; Gurfinkel, M.; Leleux, P.; Ghestem, A.; Ismailova, E.; Hervé, T.; Sanaur, S.; Bernard, C.; Malliaras, G. G. In Vivo Recordings of Brain Activity Using Organic Transistors. Nat. Commun. 2013, 4, 1575.

8 Khodagholy, D.; Gelinas, J. N.; Zhao, Z.; Yeh, M.; Long, M.; Greenlee, J. D.; Doyle, W.; Devinsky, O.; Buzsáki, G. Organic Electronics for High-Resolution Electrocorticography of the Human Brain. Sci. Adv. 2016, 2, e1601027.

9 Williamson, A.; Ferro, M.; Leleux, P.; Ismailova, E.; Kaszas, A.; Doublet, T.; Quilichini, P.; Rivnay, J.; Rõzsa, B.; Katona, G.; Bernard, C.; Malliaras, G. G. Localized Neuron Stimulation with Organic Electrochemical Transistors on Delaminating Depth Probes. Adv. Mater. 2015, 27, $4405-4410$.

10 Venkatraman, V.; Friedlein, J. T.; Giovannitti, A.; Maria, I. P.; McCulloch, I.; McLeod, R. R.; Rivnay, J. Subthreshold Operation of Organic Electrochemical Transistors for Biosignal Amplification. Adv. Sci. 2018, 5, 1800453.

11 Bernards, D. A.; Malliaras, G. G. Steady-State and Transient Behavior of Organic Electrochemical Transistors. Adv. Funct. Mater. 2007, 17, 3538-3544.

12 Laiho, A.; Herlogsson, L.; Forchheimer, R.; Crispin, X.; Berggren, M. Controlling the Dimensionality of Charge Transport in Organic Thin-Film Transistors. Proc. Natl. Acad. Sci. U. S. A. 2011, 108, 15069-15073.

13 Inal, S.; Rivnay, J.; Leleux, P.; Ferro, M.; Ramuz, M.; Brendel, J. C.; Schmidt, M. M.; Thelakkat, M.; Malliaras, G. G. A High Transconductance Accumulation Mode Electrochemical Transistor. Adv. Mater. 2014, 26, 7450-7455.

14 Mantione, D.; Del Agua, I.; Schaafsma, W.; Elmahmoudy, M.; Uguz, I.; Sanchez-Sanchez, A.; Sardon, H.; Castro, B.; Malliaras, G. G.; Mecerreyes, D. Low-Temperature Cross-Linking of 
PEDOT:PSS Films Using Divinylsulfone. ACS Appl. Mater. Interfaces 2017, 9, 18254-18262.

Håkansson, A.; Han, S.; Wang, S.; Lu, J.; Braun, S.; Fahlman, M.; Berggren, M.; Crispin, X.; Fabiano, S. Effect of (3-Glycidyloxypropyl)Trimethoxysilane (GOPS) on the Electrical Properties of PEDOT:PSS Films. J. Polym. Sci. Part B Polym. Phys. 2017, 55, 814-820.

Kim, S. M.; Kim, C. H.; Kim, Y.; Kim, N.; Lee, W. J.; Lee, E. H.; Kim, D.; Park, S.; Lee, K.; Rivnay, J.; Yoon, M. H. Influence of PEDOT:PSS Crystallinity and Composition on Electrochemical Transistor Performance and Long-Term Stability. Nat. Commun. 2018, 9, 3858.

Khodagholy, D.; Rivnay, J.; Sessolo, M.; Gurfinkel, M.; Leleux, P.; Jimison, L. H.; Stavrinidou,

E.; Herve, T.; Sanaur, S.; Owens, R. M.; Malliaras, G. G. High Transconductance Organic Electrochemical Transistors. Nat. Commun. 2013, 4, 2133.

Rivnay, J.; Inal, S.; Collins, B. A.; Sessolo, M.; Stavrinidou, E.; Strakosas, X.; Tassone, C.; Delongchamp, D. M.; Malliaras, G. G. Structural Control of Mixed Ionic and Electronic Transport in Conducting Polymers. Nat. Commun. 2016, 7, 11287.

Inal, S.; Malliaras, G. G.; Rivnay, J. Benchmarking Organic Mixed Conductors for Transistors. Nat. Commun. 2017, 8, 1767.

20 Nielsen, C. B.; Giovannitti, A.; Sbircea, D. T.; Bandiello, E.; Niazi, M. R.; Hanifi, D. A.; Sessolo, M.; Amassian, A.; Malliaras, G. G.; Rivnay, J.; McCulloch, I. Molecular Design of Semiconducting Polymers for High-Performance Organic Electrochemical Transistors. J. Am. Chem. Soc. 2016, 138, 10252-10259.

21 Giovannitti, A.; Sbircea, D. T.; Inal, S.; Nielsen, C. B.; Bandiello, E.; Hanifi, D. A.; Sessolo, M.; Malliaras, G. G.; McCulloch, I.; Rivnay, J. Controlling the Mode of Operation of Organic Transistors through Side-Chain Engineering. Proc. Natl. Acad. Sci. U. S. A. 2016, 113, 1201712022 .

22 Savagian, L. R.; Österholm, A. M.; Ponder, J. F.; Barth, K. J.; Rivnay, J.; Reynolds, J. R. Balancing Charge Storage and Mobility in an Oligo(Ether) Functionalized Dioxythiophene Copolymer for Organic- and Aqueous- Based Electrochemical Devices and Transistors. Adv. Mater. 2018, 30, 1804647.

23 Giovannitti, A.; Thorley, K. J.; Nielsen, C. B.; Li, J.; Donahue, M. J.; Malliaras, G. G.; Rivnay, J.; McCulloch, I. Redox-Stability of Alkoxy-BDT Copolymers and Their Use for Organic Bioelectronic Devices. Adv. Funct. Mater. 2018, 28, 1706325.

24 Giovannitti, A.; Rashid, R. B.; Thiburce, Q.; Paulsen, B. D.; Cendra, C.; Thorley, K.; Moia, D.; Mefford, J. T.; Hanifi, D.; Weiyuan, D.; Moser, M.; Salleo, A.; Nelson, J.; McCulloch, I.; Rivnay, J. Energetic Control of Redox-Active Polymers toward Safe Organic Bioelectronic Materials. Adv. Mater. 2020, 32, 1908047.

25 Giovannitti, A.; Nielsen, C. B.; Sbircea, D. T.; Inal, S.; Donahue, M.; Niazi, M. R.; Hanifi, D. A.; Amassian, A.; Malliaras, G. G.; Rivnay, J.; McCulloch, I. N-Type Organic Electrochemical Transistors with Stability in Water. Nat. Commun. 2016, 7, 13066. 
26 Bischak, C. G.; Flagg, L. Q.; Yan, K.; Li, C. Z.; Ginger, D. S. Fullerene Active Layers for NType Organic Electrochemical Transistors. ACS Appl. Mater. Interfaces 2019, 11, 28138-28144.

Pappa, A. M.; Ohayon, D.; Giovannitti, A.; Maria, I. P.; Savva, A.; Uguz, I.; Rivnay, J.; McCulloch, I.; Owens, R. M.; Inal, S. Direct Metabolite Detection with an N-Type Accumulation Mode Organic Electrochemical Transistor. Sci. Adv. 2018, 4, 0911.

Ohayon, D.; Nikiforidis, G.; Savva, A.; Giugni, A.; Wustoni, S.; Palanisamy, T.; Chen, X.; Maria, I. P.; Di Fabrizio, E.; Costa, P. M. F. J.; McCulloch, I.; Inal, S. Biofuel Powered Glucose Detection in Bodily Fluids with an N-Type Conjugated Polymer. Nat. Mater. 2020, 19, 456-463.

29 Savva, A.; Hallani, R.; Cendra, C.; Surgailis, J.; Hidalgo, T. C.; Wustoni, S.; Sheelamanthula, R.; Chen, X.; Kirkus, M.; Giovannitti, A.; Salleo, A.; McCulloch, I.; Inal, S. Balancing Ionic and Electronic Conduction for High-Performance Organic Electrochemical Transistors. Adv. Funct. Mater. 2020, 30, 1907657.

30 Lei, T.; Wang, J. Y.; Pei, J. Roles of Flexible Chains in Organic Semiconducting Materials. Chem. Mater. 2014, 26, 594-603.

31 Mei, J.; Bao, Z. Side Chain Engineering in Solution-Processable Conjugated Polymers. Chem. Mater. 2014, 26, 604-615.

32 Brinkmann, M. Structure and Morphology Control in Thin Films of Regioregular Poly(3Hexylthiophene). J. Polym. Sci. Part B Polym. Phys. 2011, 49, 1218-1233.

Dang, M. T.; Hirsch, L.; Wantz, G.; Wuest, J. D. Controlling the Morphology and Performance of Bulk Heterojunctions in Solar Cells. Lessons Learned from the Benchmark Poly(3Hexylthiophene):[6,6]-Phenyl- C61-Butyric Acid Methyl Ester System. Chem. Rev. 2013, 113, 3734-3765.

34 Wadsworth, A.; Hamid, Z.; Bidwell, M.; Ashraf, R. S.; Khan, J. I.; Anjum, D. H.; Cendra, C.; Yan, J.; Rezasoltani, E.; Guilbert, A. A. Y.; Azzouzi, M.; Gasparini, N.; Bannock, J. H.; Baran, D.; Wu, H.; de Mello, J. C.; Brabec, C. J.; Salleo, A.; Nelson, J.; Laquai, F.; McCulloch, I. Progress in Poly (3-Hexylthiophene) Organic Solar Cells and the Influence of Its Molecular Weight on Device Performance. Adv. Energy Mater. 2018, 8, 1801001.

Moser, M.; Thorley, K. J.; Moruzzi, F.; Ponder, J. F.; Maria, I. P.; Giovannitti, A.; Inal, S.; McCulloch, I. Highly Selective Chromoionophores for Ratiometric $\mathrm{Na}+$ Sensing Based on an Oligoethyleneglycol Bridged Bithiophene Detection Unit. J. Mater. Chem. C 2019, 7, 53595365.

36 Skompska, M.; Szkurlat, A. The Influence of the Structural Defects and Microscopic Aggregation of Poly(3-Alkylthiophenes) on Electrochemical and Optical Properties of the Polymer Films: Discussion of an Origin of Redox Peaks in the Cyclic Voltammograms. Electrochim. Acta 2001, 46, 4007-4015.

37 Sweetnam, S.; Graham, K. R.; Ngongang Ndjawa, G. O.; Heumüller, T.; Bartelt, J. A.; Burke, T. M.; Li, W.; You, W.; Amassian, A.; McGehee, M. D. Characterization of the Polymer Energy 
Landscape in Polymer:Fullerene Bulk Heterojunctions with Pure and Mixed Phases. J. Am. Chem. Soc. 2014, 136, 14078-14088.

Lyons, M. E. G. Electroactive Polymer Electrochemistry; Plenum Press: New York, 1994.

Gladisch, J.; Stavrinidou, E.; Ghosh, S.; Giovannitti, A.; Moser, M.; Zozoulenko, I.; McCulloch, I.; Berggren, M. Reversible Electronic Solid-Gel Switching of a Conjugated Polymer. Adv. Sci. 2020, 7, 1901144.

40 Cardona, C. M.; Li, W.; Kaifer, A. E.; Stockdale, D.; Bazan, G. C. Electrochemical Considerations for Determining Absolute Frontier Orbital Energy Levels of Conjugated Polymers for Solar Cell Applications. Adv. Mater. 2011, 23, 2367-2371.

41 Zozoulenko, I.; Singh, A.; Singh, S. K.; Gueskine, V.; Crispin, X.; Berggren, M. Polarons, Bipolarons, And Absorption Spectroscopy of PEDOT. ACS Appl. Polym. Mater. 2019, 1, 83-94.

Ghosh, S.; Gueskine, V.; Berggren, M.; Zozoulenko, I. V. Electronic Structures and Optical Absorption of N-Type Conducting Polymers at Different Doping Levels. J. Phys. Chem. C 2019, $123,15467-15476$.

43 DeLongchamp, D. M.; Vogel, B. M.; Jung, Y.; Gurau, M. C.; Richter, C. A.; Kirillov, O. A.; Obrzut, J.; Fischer, D. A.; Sambasivan, S.; Richter, L. J.; Lin, E. K. Variations in Semiconducting Polymer Microstructure and Hole Mobility with Spin-Coating Speed. Chem. Mater. 2005, 17, $5610-5612$.

44 Zhao, L. H.; Png, R. Q.; Zhuo, J. M.; Wong, L. Y.; Tang, J. C.; Su, Y. S.; Chua, L. L. Role of Borderline Solvents to Induce Pronounced Extended-Chain Lamellar Order in $\pi$-Stackable Polymers. Macromolecules 2011, 44, 9692-9702.

45 Wang, G.; Swick, S. M.; Matta, M.; Mukherjee, S.; Strzalka, J. W.; Logsdon, J. L.; Fabiano, S.; Huang, W.; Aldrich, T. J.; Yang, T.; Timalsina, A.; Powers-Riggs, N.; Alzola, J. M.; Young, R. M.; DeLongchamp, D. M.; Wasielewski, M. R.; Kohlstedt, K. L.; Schatz, G. C.; Melkonyan, F. S.; Facchetti, A.; Marks, T. J. Photovoltaic Blend Microstructure for High Efficiency PostFullerene Solar Cells. To Tilt or Not to Tilt? J. Am. Chem. Soc. 2019, 141, 13410-13420.

46 Kong, M.; Saha Dalal, I.; Li, G.; Larson, R. G. Systematic Coarse-Graining of the Dynamics of Self-Attractive Semiflexible Polymers. Macromolecules 2014, 47, 1494-1502.

47 Noriega, R.; Salleo, A.; Spakowitz, A. J. Chain Conformations Dictate Multiscale Charge Transport Phenomena in Disordered Semiconducting Polymers. Proc. Natl. Acad. Sci. U. S. A. 2013, 110, 16315-16320.

48 Carbone, P.; Troisi, A. Charge Diffusion in Semiconducting Polymers: Analytical Relation between Polymer Rigidity and Time Scales for Intrachain and Interchain Hopping. J. Phys. Chem. Lett. 2014, 5, 2637-2641.

49 Flagg, L. Q.; Bischak, C. G.; Onorato, J. W.; Rashid, R. B.; Luscombe, C. K.; Ginger, D. S. Polymer Crystallinity Controls Water Uptake in Glycol Side-Chain Polymer Organic Electrochemical Transistors. J. Am. Chem. Soc. 2019, 141, 4345-4354. 
50 Rivnay, J.; Ramuz, M.; Leleux, P.; Hama, A.; Huerta, M.; Owens, R. M. Organic Electrochemical Transistors for Cell-Based Impedance Sensing. Appl. Phys. Lett. 2015, 106, 043301 .

51 Dunn, L.; Basu, D.; Wang, L.; Dodabalapur, A. Organic Field Effect Transistor Mobility from Transient Response Analysis. Appl. Phys. Lett. 2006, 88, 063507.

52 Dost, R.; Das, A.; Gruel, M. Time-of-Flight Mobility Measurements in Organic Field-Effect Transistors. J. Appl. Phys. 2008, 104, 084519.

53 Sirringhaus, H.; Brown, P. J.; Friend, R. H.; Nielsen, M. M.; Bechgaard, K.; Langeveld-Voss, B. M. W.; Spiering, A. J. H.; Janssen, R. A. J.; Meijer, E. W.; Herwig, P.; De Leeuw, D. M. TwoDimensional Charge Transport in Self-Organized, High-Mobility Conjugated Polymers. Nature 1999, 401, 685-688. 
For table of contents only

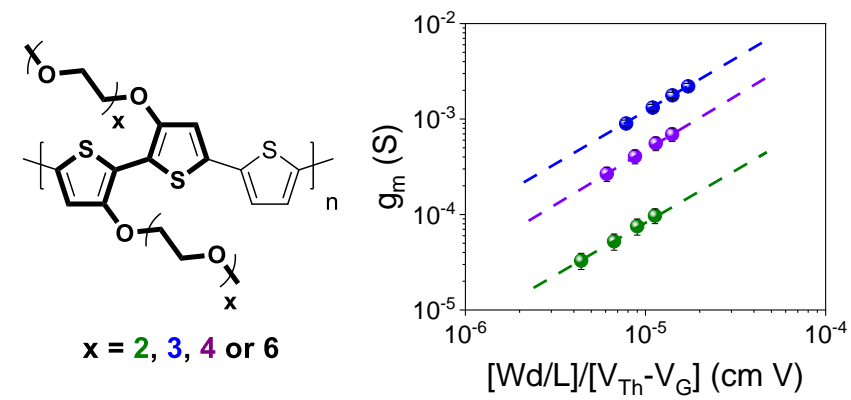

